\title{
Study on the Development of Wood Carving Industry in the Process of Urbanization Under the Background of Innovation and Entrepreneurship Reform
}

\author{
Laicheng Yang", Weitao $\mathrm{Xu}^{2}$, An Mao ${ }^{1, ~ *, ~ Y i f u ~ Y u a n ~}{ }^{1,}$, \\ ${ }^{1}$ College of Forestry, Shandong Agricultural University, Taian, China \\ ${ }^{2}$ Planning and Design Institute of Forest Products Industry of National Forestry and Grassland Administration, Beijing, China
}

Email address:

yanglcc@126.com (Laicheng Yang),mjgbw_001@163.com (Weitao Xu),dannymaoan@126.com (An Mao),yuanyf16@163.com (Yifu Yuan) ${ }^{*}$ Corresponding authors

\section{To cite this article:}

Laicheng Yang, Weitao Xu, An Mao, Yifu Yuan. Study on the Development of Wood Carving Industry in the Process of Urbanization Under the Background of Innovation and Entrepreneurship Reform. International Journal of Secondary Education. Vol. 8, No. 4, 2020 , pp. 126-130. doi: $10.11648 /$ j.ijsedu.20200804.14

Received: November 18, 2020; Accepted: December 3, 2020; Published: December 8, 2020

\begin{abstract}
Urbanization is a process in which the population is concentrated in cities and towns and thus promotes the development of cities and towns. The process of urbanization has brought about changes in rural social and economic structure, culture and values in China. These changes have a profound impact on the management status, development path, and inheritance form of wood carving. Traditional wood carving is mainly plane relief, which can be divided into thin relief, shallow relief, deep relief, high relief, multi-layer overlapping, double-sided hollow carving, sawn hollow carving, full ground carving, color wood inlaid carving, round wood relief, etc. From the farming era to the modern society, the business model of wood carving has changed from household system, factory system, and studio system. From the perspective of inheritance mechanism, the key elements of wood carving inheritance are cultural factors, industry background and family environment; the impact of urbanization on traditional wood carving is mainly reflected in the inheritance object, production mode, sales market, product attributes, and so on. Under the background of new urbanization, and innovation and entrepreneurship, this paper discusses the protection and inheritance of traditional wood carving technology, and at the same time, it should use its core value as local resources to shape and promote the sustainable development of rural society. This study also will provide important information for the innovation and entrepreneurship reform of related forestry majors.
\end{abstract}

Keywords: Urbanization, Wood Carving, Arts and Crafts, Innovation and Entrepreneurship

\section{Introduction}

According to definition of urbanization, urbanization is a process in which the population is concentrated in cities and towns and thus promotes the development of cities and towns. Along with this process is a major change in the country's economic structure, social structure, mode of production and lifestyle. Rapid urbanization will inevitably have a greater impact on the traditional arts and crafts industry [1-2]. In this regard, Wood carving is a typical example. Wood carving is an important category of traditional carving technology. Wood carving is a kind of folk art classified by carving materials. Generally, fine, flexible and non deformable tree species are selected for carving. Generally, it also refers to the carving crafts carved with wood. Wood carving has a long history in China. It is divided into many types because of its wide range of application and decoration, various forms of expression, different wood texture and various types of carving techniques. All kinds of wood carving crafts not only contain Chinese auspicious culture, but also embody high artistic value of wood carving. People not only can be used for collection, but also at home, office, or restaurants, restaurants, leisure and other public places excellent decorations. Through the investigation of wood carving industry development and artists' living conditions, it is of practical significance to explore the modern transformation of traditional arts and crafts and craftsmen and play the role of arts and crafts in the 
process of "people-centered urbanization". This study also provides valuable information for the innovation and entrepreneurship reform of related forestry majors.

\section{Historical Review and Artistic Features of Wood Carving}

Traditional wood carving is mainly plane relief, which can be divided into thin relief, shallow relief, deep relief, high relief, multi-layer overlapping, double-sided hollow carving, sawn hollow carving, full ground carving, color wood inlaid carving, round wood relief, etc. it has rich levels and basic characteristics of plane decoration, and has light color, no dark paint, and retains the natural texture and color of logs, and elegant style, which is called "white wood carving " [3].

Wood carving works of art generally do not add color painting, more use the natural color transparent varnish coating, in order to retain the natural color of white wood. Therefore, most of the materials are basswood, white peach, cinnamomum camphora, gingko and so on. They pay attention to creativity and "painting", which has high artistic value. The themes and contents are mostly historical stories and folklore [4]. The picture design is in the same vein as the traditional Chinese painting line drawing flowers. The pattern decoration is rich and varied. There are also rich carving decorations, including figures, landscapes, flowers and birds, animals and so on. In terms of artistic techniques, wood carving deals with perspective with high-level, far-reaching and plane dispersion, and its composition features are scattered perspective or bird's-eye perspective of traditional Chinese painting. In other words, in a certain plane and space range, it can show more abundant contents than western relief, and can fully display the content of the picture [5].

Table 1. Wood carving in different development stages of production organization, marketing and product types.

\begin{tabular}{|c|c|c|c|}
\hline Year & Form of production organization & Marketing & Production type \\
\hline Before 1950 & Household system & $\begin{array}{l}\text { Domestic construction of traditional temples and } \\
\text { houses }\end{array}$ & $\begin{array}{l}\text { Wooden and carved components of } \\
\text { traditional temple buildings }\end{array}$ \\
\hline $1950-1970$ & $\begin{array}{l}\text { Wood carving group, wood carving bamboo } \\
\text { weaving craft factory, loudian village } \\
\text { processing point }\end{array}$ & $\begin{array}{l}\text { More than } 80 \text { countries and regions including } \\
\text { Southeast Asia, Europe and the United States }\end{array}$ & Architectural decoration \\
\hline 1980-1990 & $\begin{array}{l}\text { Several enterprises, a group of wood carving } \\
\text { artists were employed to all parts of the country }\end{array}$ & $\begin{array}{l}\text { Domestic auditorium, hotel, restaurant, museum, } \\
\text { Singapore, Germany and other restaurants, } \\
\text { restaurants }\end{array}$ & Architectural decoration \\
\hline $1990-2000$ & $\begin{array}{l}\text { There are more than } 100 \text { processing points in } \\
\text { rural areas, and each village has one processing } \\
\text { point on average }\end{array}$ & $\begin{array}{l}\text { The second level wholesale market of provinces } \\
\text { and cities in China and Southeast Asia and other } \\
\text { countries and regions }\end{array}$ & $\begin{array}{l}\text { Architectural decoration, Furniture } \\
\text { decoration }\end{array}$ \\
\hline 2000-current & $\begin{array}{l}\text { There are more than } 3100 \text { wood carving } \\
\text { factories, and the number of processing sites in } \\
\text { the village is gradually decreasing }\end{array}$ & Wood carving market & $\begin{array}{l}\text { Architectural decoration, mahogany } \\
\text { furniture decoration, single piece } \\
\text { wood carving creation }\end{array}$ \\
\hline
\end{tabular}

\section{The Development and Change of Wood Carving in the Process of Urbanization}

\subsection{Production Mode of Household Form}

Household production model reflects the basic structure of China's grass-roots society, that is, in the production of agricultural sidelines, households become the most basic organizational unit. The production of traditional woodcarving in loudian village is based on this family system [6]. Under the background of the difference order pattern of rural society, the relationship network formed by blood ties provides convenience for the transfer of skills, and family and internal family learning is the main way of its transmission. Most of the older woodcarvers are surnamed Lou. They learn skills from their parents or relatives. This kind of inheritance mode gradually expands to other villagers in the village, and finally forms the "family" inheritance mode with the whole village as the radiation scope.

The household production mode has many structural advantages. First of all, household production can flexibly adjust the working hours according to the agricultural production cycle and the order situation, and flexibly form mutual aid groups when necessary, instead of having to carry out uninterrupted production in a fixed period of time as the factory does. Secondly, household production mode can save a lot of costs, including the cost of internal supervision and management, transaction costs and personnel turnover costs. Thirdly, the household model eliminates the intermediate link, which is convenient for communication with customers. Traditionally, wood carving customers are mostly carved components used for temple building and house building. They need customized products, which is exactly what the household system can provide. As time goes on, customers and carving suppliers have established a relationship of mutual trust, sometimes even across generations [7].

\subsection{Factory Production Mode}

Before the cooperative period, wood carving was mainly inherited by masters and apprentices. After the reform and opening up, temples and ancestral halls need to be rebuilt, which has led to the rapid development of wood carving. Wood carving factories have been set up in many towns. During the peak period, almost every village has a processing point, specializing in the production of wood carving. These 
township enterprises developed from rural sideline business effectively combined various production factors in rural areas, which led to the rapid development of wood carving [8]. As shown in Table 1, the production organization, sales and product types of wood carving in different development stages are listed. With the change of production mode, the inheritance mode of wood carving technology has also changed, from the traditional master with apprentices, family inheritance to enterprise inheritance, which is, recruiting apprentices to work in the factory. During the period of planned economy, collective enterprises and village enterprises trained a large number of carving talents. After the disintegration of collective enterprises, these talents returned to the countryside to set up workshops or factories, and became the backbone of wood carving inheritance [9].

After 2000, with the popularity of machine carving products, the types of wood carving products expanded from architectural decoration to furniture decoration and handicrafts. In order to obtain more profits, enterprises will set up factories under their own management to produce a large number of standardized products; some companies use the "internal contract" system, that is, some production links are contracted by foremen as a whole or employ workers who are priced on a piece by piece basis. This method is more suitable for wood carving, which has complex process, small batch production and depends on craftsman's skills. It has the advantage of reducing the burden of management and supervision. At the same time, like the factory system of vertical production, the quality and delivery date can be controlled in the whole production process. With the widespread adoption of this vertical production mode, the wood carving industry structure is that the scale of enterprises is expanded while the number is reduced, and the enterprises are generally located in the industrial center of the city. Wood carving from rural areas to urban concentration, production sites from family workshops to factories, process from scattered to centralized trend is more obvious. A large number of specialized production factories gathered in Nanma and Hengdian. In the early stage of reform and opening up, the situation of outsourcing a large number of tasks to external processing sites gradually decreased, and the weakening of subcontracting system further led to the reduction of industrial activities in rural areas [10].

In wood carving industry, the influence of the wide application of carving equipment on work and remuneration is one of the controversial topics. The original traditional wood carving art has become a process in the industry to some extent, and the craftsman has become the workers on the production line. In the study of traditional wood carving, the apprentice should start from polishing, and then gradually increase the difficulty according to the quality of the work completed, until it can replace the master. After the machine replaced the manual embryo, the apprentice's work has basically been refining and polishing on the wood carving that has been shaped, and there is very little embryo work for the apprentice to learn. This method improves the production efficiency and saves a lot of labor costs, but also leads to many woodcarving masters do not need to bring apprentices, many apprentices cannot complete a work independently after a long time of learning.

Woodcarving reflects the complex relationship between art and technology, including the continuation of skills and tacit knowledge in the process of inheritance. At present, in the factory production, the rich content of woodcarving itself has not been inherited, and the enthusiasm of woodcarving artists is weaker than other production forms. Compared with famous masters or studios with fixed customers, the craftsmanship of wood carving workers in the factory is not known to the market and end users, and their work stability is greatly affected by factory orders.

\subsection{The Development of Studio System}

Over the past decades, wood carving artists have been able to successfully adjust and continue their business according to the changes of social environment and needs. In addition to wood carving brand and historical precipitation, an important factor is that the atmosphere of recognition for creative work expressing personal experience, background and characteristics has been formed.

Under the family system, artists pay attention to income and ensure the quality of products to maintain their reputation. Under the factory system, artists are generally in a passive state because they are out of touch with the market. Under the studio system, artists pay more attention to honor and creativity than in the past. Handicraft industry is the most satisfactory form of employment in modern society, and gives workers the highest level of personal dignity. Although the history and culture of each country is different, the feeling of young people is no different from that of artists in other developed countries. The studio provides a platform for creating personal narrative of self-development and self-realization, and shows the vitality of innovation.

\section{The Change of Inheritance Mechanism of Wood Carving Industry in the Process of Urbanization}

\subsection{The Crisis of Traditional Wood Carving Inheritance}

The process of urbanization has brought opportunities to the development of wood carving industry, but also produced many problems. The comprehensive effect of the "pull" of industrialization and urbanization and the "thrust" of rural surplus labor force increase the flow of rural population to urban and rural areas, and lead to different degrees and types of hollow. Therefore, the pattern of farmers as the main body has changed, which makes the current rural wood carving inheritance fall into the dilemma of "the absence of farmers as the main body".

In the past, under the influence of the original concept in rural areas, after finishing junior high school, villagers would let their children choose to learn wood carving, architecture or textile skills. With the development of economy and the popularization of cultural knowledge, most villagers hope 
that their children can enter a good university. This is the standard way for many people to find a good job. At present, the wood carving practitioners are mainly migrant workers. Few of the local people born after the 1980s are engaged in this industry.

\subsection{The Causes of the Change of Inheritance Mechanism of Wood Carving in the Process of Urbanization}

\subsubsection{External Factors Influencing the Inheritance of Wood Carving Skills}

In terms of professional attribute, wood carving craftsman has always been regarded as a carpenter, and the inheritance of wood carving skill depends more on external factors. According to the different aspects of influencing factors of wood carving inheritance, it can be divided into three dimensions: cultural factors, industry factors and family factors.

Cultural factors here refer to all the consciousness, tradition, knowledge, customs and their renewal and inheritance, including clan consciousness, local ecological knowledge and ethics, morality and code of action, happiness and sense of achievement, etc., which are externally expressed as myths, allusions, festivals, etc. The influence of local cultural factors on the inheritance of wood carving is imperceptible. On the one hand, the countryside brings people social consciousness and becomes the place where various arts and crafts occur and develop; on the other hand, the village is not only the production place of wood carving, but also the consumption place of wood carving in agricultural society.

Industry factors include the income from wood carving production, the situation of local enterprises and leaders, and the honor and status of artists. The primary purpose of handicraft production is to make a living. The nature of folk wood carving artists is basically full-time, so the economic benefit of wood carving industry is the priority factor for craftsmen. When the income situation is good, there are more employees; when the economic situation is bad, many artists will consider changing their careers and looking for another way out, which will naturally affect the inheritance. Secondly, the inheritance of wood carving skills is determined by the demonstration role of local leaders or the employment opportunities generated by local enterprises. To a certain extent, the wood carving group established in loudian village is the source of the formation and development of wood carving village; in the follow-up, under the demonstration effect of enterprises and leaders in each era, the intersection of various network relationships in the village finally contributed to the formation of the professional village of wood carving in loudian. In addition, the good reputation and sense of achievement of personal products in the market are also valued by artists. Wood carving artists have long sold their products in the market. They link their personal credit with their products. Their works play an important role in the spread of wood carving artists' reputation. Interest and the need to communicate with people, especially in the production and inheritance of modern wood carving began to play a more and more important role. Wood carving artists do not simply consider economic benefits, but hope to be recognized through communication and constantly improve their own level [11].

Family factor is the most direct and intuitive experience of the object, including education, contact with parents, relatives, neighbors, friends and so on. According to the status realization models, the education level is the most important factor affecting the professional status, followed by the first professional status after taking part in the work. The occupation of their parents also has an important impact on the occupation. From another point of view, in the case of education itself does not build the corresponding handicraft inheritance system, the current academic education challenges the inheritance order of traditional wood carving technology.

\subsubsection{The Internal Factors Influencing the Inheritance Mechanism of Wood Carving}

In the farming society, agriculture and forestry and small-scale handicraft industry are the main pillars of China's rural areas, and almost all the living goods can be bought in closed rural units. Now, due to the non-agricultural economic structure, the comparative benefits of farmland management are gradually reduced. Farmers hope to participate in other agricultural production activities less, such as wheat, corn and other crops that occupy less labor force, so as to have time to engage in work that can bring higher income.

In terms of lifestyle, wood carving artists now tend to live in cities to obtain more resources. In the past, the production of woodcarving was mainly oriented to the needs of rural temples. Now the market has changed. With the consumption of products from rural areas to cities, wood carving artists tend to move to the city, engaged in full-time, professional production. They realize that they can display and promote their products with the help of a broader platform of the city, and they can get more information and opportunities to live in the city. Luzhai old street and other tourist attractions and shops along the street provide display space for wood carving artists, and buyers from all over the country can easily find them in the city. Wood carving industry is gradually losing the property of small-scale peasant economy, in which the city plays an important role. With the younger groups of artists, they are more likely to integrate into the city and accept new knowledge. They can combine their works with the modern society, and walk out of their own unique style between tradition and innovation [12].

In terms of status, wood carving artists have long been ignored. Now, the status of craftsmen has changed a lot. Wood carving is an advantageous traditional industry. The government and organizations often hold or organize to participate in various intangible cultural heritage exhibitions, arts and crafts fairs, skills competitions, etc., and regularly select arts and crafts masters at all levels. These activities provide a platform for folk wood carving artists to display and broadcast. Although there are some disputes on the 
selection of masters in the society, it is undeniable that wood carving artists have been widely concerned and their social status has been greatly improved.

In terms of production, although the content of handwork has been gradually valued, in reality, machine production has replaced the work of many ordinary craftsmen. To own machinery, we must have capital and bear corresponding risks, which is obviously beyond the capacity of most ordinary craftsmen. For example, in terms of wood carving, due to the emergence of engraving machines, the number of manual work in woodcarving, especially relief carving, is greatly reduced. Only a small amount of labor is used in the finishing stage. The production has gradually shifted from scattered farmers' processing to centralized factory production, and the workplace has moved from home to factory with large equipment.

With the change of the times, the attributes of folk arts and crafts have changed, especially the artifacts made for the life of ordinary people are replaced by a large number of industrial products. At the moment when machine mass production is the mainstream, the surviving arts and crafts products need to emphasize the difference between the manual and the unique machine. For example, with the change of product orientation, the "public attribute" of wood carving has changed, and its artistry and individuality are gradually enhanced. The change of product attributes should also change the inheritor's own quality, production mode and sales channels. Therefore, under the new background, especially in the environment of expanding production order and market order, it is of typical significance for folk artists to adapt and transform and make the traditional wood carving better move towards the track of commodity economy.

\section{Summary}

From the perspective of development, the essence of urbanization is the urbanization of human beings. The revitalization of rural areas should be positioned in industries that make communities independent of urban centers and can maintain and develop themselves. Local, organic and pure assets rather than human culture are the basic resources for employment regeneration.

As mentioned above, in history, the recognition of creative work that expresses personal experience, background and characteristics is the core value of wood carving. Wood carving needs to transform and develop the ability of innovation and creativity to meet the needs of consumers. Under the background of new urbanization, and innovation and entrepreneurship, digging into this basic system and original tradition can provide more platforms for the development of the new "studio" system in rural areas, and transform its formal language into modern art patterns in line with the development of the times, or help to revitalize traditional crafts and reactivate rural society. This study also will provide important information for the innovation and entrepreneurship reform of related forestry majors.

\section{Author Contributions}

The Manuscript was written through contributions of all authors. All authors have given approval to the final version of the manuscript.

\section{Conflicts of Interest}

The authors declare that they have no competing interests.

\section{References}

[1] Feng M. X, Xie Q (2020) Transformation strategies of woodcarving enterprises under the background of "internet plus". China Forestry Products Industry, 57 (4): 68-70.

[2] Xu H. F, Dai X. D, Ye L, Zhang Y, Wang J. Y (2019) Problems and suggestions on the Dongyang Mahogany furniture industry in Zhejiang province. China Forestry Products Industry, 46 (6): 41-44.

[3] Xue Y. J (2018) Application of Cantonese style furniture design based on woodcarving pattern art. Furniture \& Interior Design, 12: 7-9.

[4] Xu H. F, Wang J. Y, Fan C, Jiang X. Y (2017) Research on the practice path and promotion strategy. Furniture \& Interior Design, 1: 72-73.

[5] Li Q (2016) Application of traditional woodcarving art in modern interior design. Packing Engineering, 37 (12): 41-44.

[6] Yan Z. H, Li K. Z (2019) Research on Module System of Ming-style Furniture. China Forestry Products Industry, 46 (7) 44-47.

[7] Gao W. X, Wu Z. H, Yu J. H (2019) Multidimensional preference analysis of su-style furniture wood carving in Ming and Qing dynasties. China Forestry Products Industry, 46 (7): 39-43.

[8] Yu J. H, Gao W. X, Wu Z. H (2019) Relevance analysis between the proportion of woodcarving decoration and visual perception of su-style furniture in Ming and Qing Dynasties. China Forestry Products Industry, 56 (12): 52-57.

[9] Gao W. X, Wu Z. H, Yu J. H (2019) Analysis on the characteristics of traditional handicraft of woodcarving by su-style furniture in Ming and Qing dynasties. China Forestry Products Industry, 56 (9): 43-47.

[10] Zhao W. S (2011) Application of traditional wood carving in interior designing art in the application of modern furniture design in China. Science \& Technology Information, 28: 252.

[11] Li H. B, Lin Z. F (2019) Study on forestry industry ecology based on circular economy. Jiangxi Agriculture, 12: 88-89.

[12] Zhang Z. Z (2019) Theoretical Logic of the "Material Circulation and Reutilization" Thought: Based on the dimension of Marxist Green Development. Journal of Central South University of Forestry \& Technology (Social Sciences), 13 (1): 12-17. 